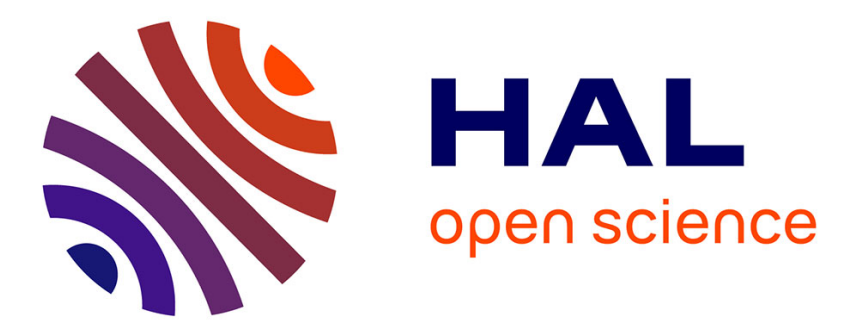

\title{
Accelerated laboratory test to study fungal biodeterioration of cementitious matrix
}

\author{
Virginie Wiktor, F. de Leo, C. Urzi, René Guyonnet, Philippe Grosseau, Eric
}

Garcia-Diaz

\section{- To cite this version:}

Virginie Wiktor, F. de Leo, C. Urzi, René Guyonnet, Philippe Grosseau, et al.. Accelerated laboratory test to study fungal biodeterioration of cementitious matrix. International Biodeterioration and Biodegradation, 2009, 63 (8), pp.1061-1065. 10.1016/j.ibiod.2009.09.004 emse-00431106

\section{HAL Id: emse-00431106 https://hal-emse.ccsd.cnrs.fr/emse-00431106}

Submitted on 10 Nov 2009

HAL is a multi-disciplinary open access archive for the deposit and dissemination of scientific research documents, whether they are published or not. The documents may come from teaching and research institutions in France or abroad, or from public or private research centers.
L'archive ouverte pluridisciplinaire HAL, est destinée au dépôt et à la diffusion de documents scientifiques de niveau recherche, publiés ou non, émanant des établissements d'enseignement et de recherche français ou étrangers, des laboratoires publics ou privés. 


\title{
Accelerated laboratory test to study fungal biodeterioration of cementitious matrix
}

\author{
WiKTOR (1)(2) , V. ; De LeO(3) , F. ; URZì(3) , C. ; GUYONNET(1) (*), R. , GrosseAU(1)(*), PH. ;
} GARCIA-DIAZ(4), E.

(1) Département PMMC (Poudres et Matériaux Multicomposants), Centre SPIN. LPMG UMR CNRS 5148. Ecole Nationale Supérieure des Mines de Saint-Etienne 158, Cours Fauriel. 42023 Saint-Etienne Cedex 2.

(2) Delft University of Technology, Faculty of Civil Engineering and Geosciences, P.O Box 5048, 2600GA Delft, The Netherlands

(3) Department of Life Sciences, Sect. of Microbiological, Genetic and Molecular Sciences, University of Messina, Salita Sperone 31, 98166

(4) Centre des Matériaux de Grande Diffusion, Ecole des Mines d'Alès, 6 avenue de Clavières, 30319 Alès Cedex, France

(*) guyonnet@emse.fr, grosseau@emse.fr

Keywords:

Biodeterioration ; fungi; cement ; accelerated laboratory test ; PAS staining.

\section{Paper relevance;}

The relevance of this paper is first the combination of the methods used for accelerated weathering of the matrix which leads to an important surface $\mathrm{pH}$ decrease in 30 days. Then, the originality of this paper is that the test presented necessitates only three months of experiment to obtain results, which is shorter than other test developed to date to study fungal biodeterioration.

\begin{abstract}
The present study aimed to develop an accelerated laboratory test to study the biodeteriorative effect of different fungal strains to a cementitious matrix. The test developed in this study permits to obtain a rapid fungal development on cement specimens. Three months of experiments only are needed to obtain first results, which is rather shorter than other test developed to date to study fungal biodeterioration. Results are mainly related to aesthetical biodeterioration. Results show that in these experimental conditions, fungal growth occurs since the first week of incubation. Stereomicroscopy observations showed that microbial growth was noticed only on the surface of specimens, while PAS staining revealed the real extent of microbial growth on and within the matrix as later confirmed by SEM observations of cross section showing the penetration of hyphae inside the matrix. Test can be used with short time of incubation, to test and to compare bioreceptivity of cement based materials; and several months of incubation should allow the study of mechanisms involved in biodeterioration
\end{abstract}

\section{Introduction}

Microorganisms - bacteria, cyanobacteria, fungi, algae, and lichens - are liable to grow on building materials. Biological activity contributes to deterioration of building material, and its interaction with physico-chemical mechanisms is considered central to understanding the long term deterioration (Saiz-J imenez, 1997). Physical, chemical, and biological agents act in co-association, ranging from synergistic to antagonistic, to deteriorate stone (Warscheid and Braams, 2000). 
Fungi are among the most harmful organisms associated to biodeterioration of organic and inorganic materials (Urzi et al., 2000a,b). Their occurrence on the stones is reported to be combined not only with aesthetic spoiling of the monuments, due to colour changes such as patina or black spots, but also there is strong evidence that these organisms are able to colonize deeper cracks, cause crater shaped lesions, chipping and exfoliation of the rock surface combined with the loss of materials (Wollenzien et al., 1995; Urzi et al., 2000b). May et al. (1993) listed fungi among major agents of microbial deterioration of building stones. Mineral substrates exposed to environmental stresses such as wind erosion, direct rain wash off, lack of organic nutrients and are refractory to rapid mycelial growth. To overcome these limitations, some fungal groups have abandoned their branched hyphal elongation system (which is more appropriate to the penetration and utilization of substrates) and have adopted microcolonial or yeast-like growth (Wollenzien et al., 1995). The smaller, compact shapes are more thermodynamically efficient especially in terms of protecting against heat and desiccation (Gorbushina, 2007).

In general, two main groups of fungi are usually isolated from rock surfaces (De Leo and Urzì, 2003): (i) one group includes species of the genera of Hyphomycetes and Coelomycetes among which are included those that do not produce melanin, like Fusarium, Penicillium, Aspergillus, and those that are black pigmented like Alternaria, Ulocladium, Cladosporium melanin producers. They are fast growing fungi. (ii) The second group includes the so-called black yeasts and meristematic fungi. Taxonomically, they are a wide and heterogeneous group of black pigmented fungi that share common characteristics such as the presence of melanins within the cells (swollen cells), hyphae and/or spores. The production of melanin and the meristematic development allow them to survive in stressed environmental conditions like low humidity and high sun irradiation (de Hoog, 1993). For this group of fungi is also used the term of rock-inhabiting fungi to underline the exclusive isolation of many of them from rock surface (De Leo and Urzì, 2003). The black fungi have the capacity to: (i) settle on the rocks surface, (ii) attach firmly to the surface and (iii) penetrate deeper into the rock. The major aesthetic damage, however, may occur when environmental conditions do not force fungi into the crevices, but due to favourable conditions for fungal growth they spread over the rock surface (Diakumaku et al., 1995).

In Civil Engineering the most widely used material is concrete for different kind of application: bridge construction, sewer pipes, buildings and in some case during restoration of Cultural Heritage Monuments. Cement plays an essential role in concrete works behaviour, because it provides its mechanical resistance (Guillon, 2004).

Cement based materials are porous, may contain organic adjuvants, and thus possess an important primary bioreceptivity. Bioreceptivity, as defined by Guillitte (1995), is the totality of materials properties that contribute to the establishment, anchorage and development of fauna and/or flora. Primary bioreceptivity is the initial potential of colonisation (Guillitte, 1995).

To preserve constructions from fungal colonisation and to act efficiently against fungal biodeterioration, it is necessary to have a better understanding of biodeterioration mechanisms and its effects on materials properties. At the moment, tests to study biodeterioration of building materials exist. Among them some were developed without accelerated weathering of the matrix leading to experiment time ranging from 7 to 15 months (Oshima et al. 1999; Urzì and De Leo 2007), while some focus on qualifying aesthetic evolution of external wall surface exposed to algal colonisation (Escadeillas et al. 2007), or studying the matrix bioreceptivity only (Nielsen et al. 2004; Shirakawa et al. 2003). To our knowledge, to date, only de Moraes Pinheiro and Ribas Silva (2003) studied the impact of 
colonisation by one fungal strain on the microstructure in the mortar phase of a normal concrete.

The aim of this study is to develop an accelerated laboratory test which allows us to compare the growth of three fungal strains and the biodeterioration of a cementitious matrix. We brought particular attention to accelerate the matrix weathering so as to not exceeding 3 months of experiment. Three fungal strains were selected for the test in order to represent main kind of fungi involved in biodeterioration in natural environment (de la Torre et al., 1991; Sterflingler 1995; Wollenzien et al., 1995; Garcia Valles et al., 1997; Warscheid and Braams, 2000; Urz̀ et al., 1998, 2001): Alternaria alternata MC342 to represent an hyphomycete, melanin-producer Exophiala sp. (MC843) for yeast-like fungi, and Coniosporium uncinatum (MC 557) as meristematic fungi.

\section{Materials and Methods}

\subsection{Matrix preparation}

This study was conducted with ordinary white Portland cement CEM I $52.5 \mathrm{R}$. The water/cement mass ratio is 0.55. Hardened cement paste samples are shaped as parallelepipeds (dimension $1 \times 2.5 \times 8.5 \mathrm{~cm}$ ). Samples were demolded 24 hours after casting and stored for 28 days at $100 \%$ relative humidity, at room temperature. Accelerated weathering is performed with carbonation only for 48 hours, or carbonation (48 hours) followed by leaching operation (28 days) as described by Wiktor et al. (2006).

\subsection{Fungal strains and media}

A. alternata (MC342) and Exophiala sp. (MC843) were isolated from Bhubaneswar temple in India in 2006 (unpublished data) using the adhesive tape method (MAT) as described by Urzi and Albertano (2001). A little square of adhesive tape (about $5 \mathrm{~mm}^{2}$ ) was streaked in DRBC agar (Oxoid) and incubated at $28^{\circ} \mathrm{C}$ until growth. C. uncinatum MC557 was isolated from Carrara marble statue located in the court-yard of the Messina Museum, Italy (De Leo et al., 1999). These isolated strains were kept in the collection of Department of Life Sciences in Messina, Italy.

A. alternata was cultivated in solid medium (Potato Dextrose Agar - PDA, Oxoid) for 5 days at $26^{\circ} \mathrm{C}$. Exophiala sp. and C. uncinatum were cultivated in liquid medium (Malt Extract Broth - MEB Oxoid) for 5 days at $26^{\circ} \mathrm{C}$.

Nutritive medium used for biodeterioration test is composed of $1 \mathrm{x}$ concentrated Yeast Nitrogen Broth (YNB) (Difco) plus the addition of Glucose $0.01 \%$.

\subsection{Fungal units suspension}

Fungal colonies growing in solid medium were scraped from the agar surface and conidia suspended in physiological solution $(0.9 \%$ of $\mathrm{NaCl}$ in distilled water), while the cultures in liquid medium were directly transferred in physiological solution. Each suspension was centrifuged 15 minutes at 2095g (3000 rpm with a Beckman and Coulter Allegra X-12R centrifuge - 4750 A rotor). Centrifugation pellet were put in suspension in $1 \mathrm{ml}$ of physiological solution. The number of fungal units was determined through a direct microscopic count in a counting chamber (Bürker chamber, ProSciTech, Australia) and adjusted at a concentration of $8.7 \times 10^{5}$ fungal units/ $\mathrm{ml}$ in YNB $1 \mathrm{x}+$ Glucose $0.01 \%$ medium.

\subsection{Biodeterioration test}

\subsubsection{Experimental set up}

Polyethylene boxes were used for test 9.5 x 9.5 x $9.5 \mathrm{~cm}$. In order to keep humidity inside box, bottom was covered by vermiculite, paper sheet was disposed on it to avoid the direct contact between specimens and vermiculite (Fig. 1). Boxes were autoclaved 15 minutes at $120^{\circ} \mathrm{C}$, then 
International Biodeterioration \& Biodegradation, 2009, 63(8), 1061-1065

doi: 10.1016/j.ibiod.2009.09.004

sterile water was added on vermiculite to wet it. Two specimens of each matrix were disposed in each box.

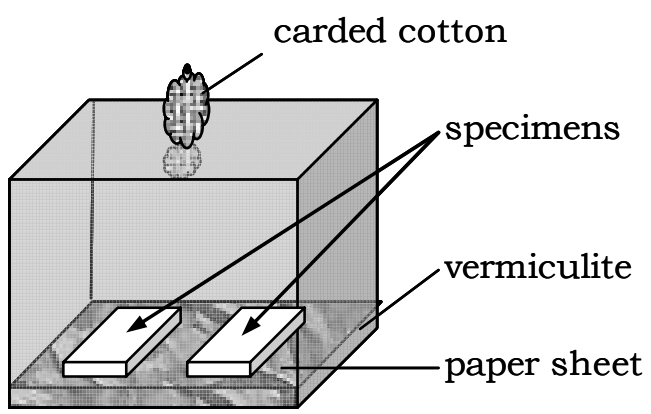

Figure 1: Experimental set up for biodeterioration test

\subsubsection{Inoculation}

Each specimen was inoculated with $1.5 \mathrm{ml}$ of fungal units suspension, except controls (only 1.5 $\mathrm{ml}$ of sterile medium). Inoculation was performed in duplicate, thus for each strain, 6 specimens were inoculated ( 2 unweathered, 2 carbonated, 2 carbonated and leached), and placed in 3 different boxes. Boxes were incubated at $26^{\circ} \mathrm{C}$.

\subsection{Analyses}

\subsubsection{Stereomicroscopy observations}

In order to monitor fungal growth during test, the surface of each specimen was observed once a week with stereomicroscope (Leica, Wild M10).

\subsubsection{Sampling of specimens}

After four weeks of incubation, one specimen of each box was taken and broken in small pieces for Periodic Acid Schiff staining and Scanning Electron Microscopy (Fig 2).

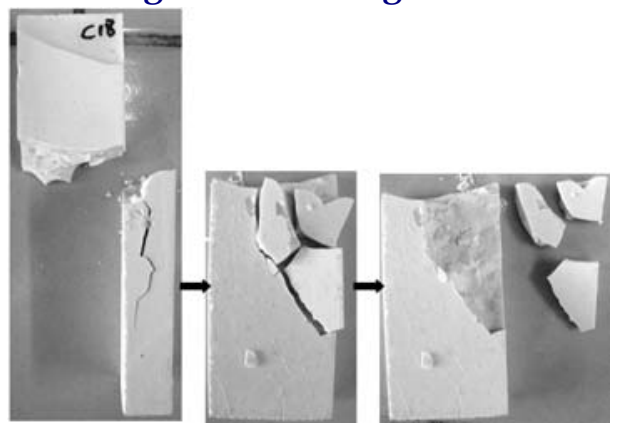

Figure 2: Example of specimen broken to carry out PAS staining and SEM observations to assess the microbial colonisation

\subsubsection{Periodic Acid Schiff (PAS) staining}

PAS staining was performed on samples as reported by Urzi and Albertano (2001). Using this procedure, compounds such as extracellular polymeric substances (EPS), glycogen, starch, cellulose, chitin, mucin, protein-carbohydrates complexes, and glycolipids appear red. Samples were fixed with 70\% (v/v) ethanol for 2 hours, then first transferred in $1 \%(\mathrm{w} / \mathrm{v})$ periodic acid for 5-8 min then in ethanol 70\% (v/v) for $5 \mathrm{~min}$. Samples are rinsed $5 \mathrm{~min}$ with distilled water and transferred 10 min to Schiff's reagent, then transferred to $0.6 \%(\mathrm{w} / \mathrm{v})$ sodium metabisulfite 3 min 2 times. They were washed twice in distilled water for 5 min each, and then transferred to $70 \%(\mathrm{v} / \mathrm{v})$ ethanol for $35 \mathrm{~min}$. 


\subsubsection{Scanning Electron Microscopy (SEM)}

Fixation of samples was performed overnight at $4^{\circ} \mathrm{C}$ in buffered aldehyde fixative $2 \%(\mathrm{w} / \mathrm{v})$ formaldehyde (P6148, Sigma). Samples were then washed 3 times in $0.01 \mathrm{M}$ phosphate buffer (0.01M NaH2PO4.H2O, 0.01M Na2HPO4, pH 7.2) for 10 min each. Dehydration was made in graded ethanol series (70, 85, 95\% (v/v) and in anhydrous ethanol (100\%) for 15 minutes each). Samples were air dried and then coated with gold for SEM observation (JEOL 840 SEM).

\section{Results and discussion}

First, relating to results from stereomicroscopy observations, no microbial growth was observed on controls for all specimens (weathered or not). In the same way, no microbial development was noticed on the surface of non-weathered specimens, no matter the inoculated strain.

For carbonated specimens, the growth of Exophiala sp. was noticed in the third week of incubation. A. alternata development started in the first week of incubation, and the growth increases until the fourth week. Hyphae and spores production were observed on the specimens' surface (Fig. 3d,e). Development of C. uncinatum was noticed in the second week of incubation and increased until the fourth week. Development of a pink coloured contamination was observed on the surface of specimens inoculated with Exophiala sp., A. alternata and C. uncinatum. Nevertheless, the presence of this contamination doesn't seem to interfere with fungal development.

Relating to carbonated then leached specimens, the strains grew faster; and therefore the development of Exophiala sp., A. alternata and C. uncinatum was observed from the first week of incubation. After four weeks of incubation, Exophiala sp. growth was characterized by numerous spots on surface (Fig. 3b); the one of C. uncinatum was homogeneous and increased from the first until the fourth week (Fig. 3c).
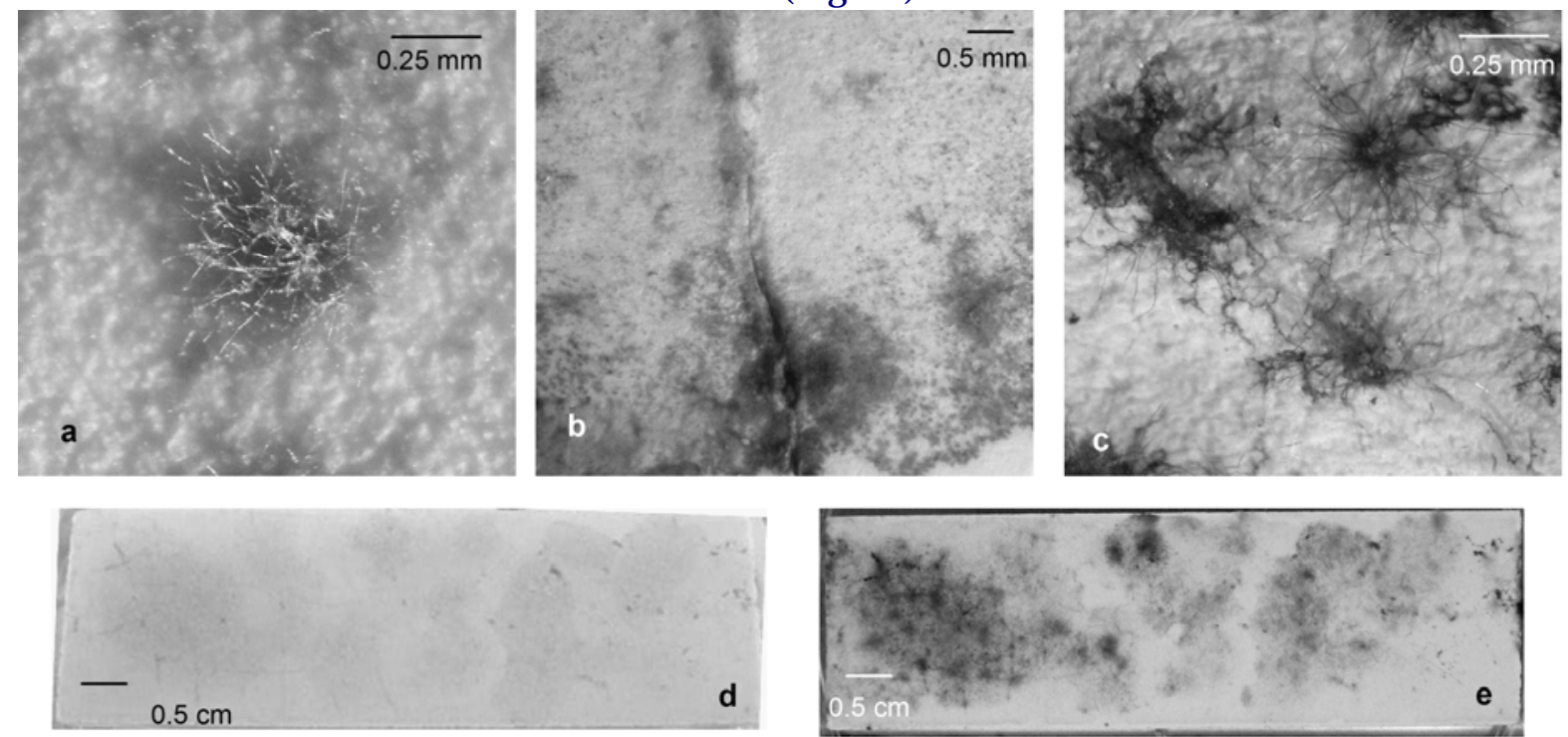

Figure 3 : Direct observations of specimens during biodeterioration test, a) and b) carbonated then leached specimen inoculated with Exophiala sp. after 1 week a), after 4 weeks b), c) carbonated then leached specimen inoculated with Coniosporium uncinatum after 4 weeks, d) and e) Carbonated specimen inoculated with Alternaria alternata after inoculation d), after 4 weeks (e).

Decrease of surface $\mathrm{pH}$ increases considerably matrix bioreceptivity, microbial colonisation is observed on some carbonated specimens and on all carbonated then leached specimens. 
Carbonation is the most common chemical reaction influencing cement-based materials in natural environmental scenarii (Macias et al., 1997; Gervais et al., 2004) that's why accelerated weathering of matrix is generally performed by carbonation (Dubosc, 2000, Shirakawa et al., 2003; de Moraes Pinheiros and Ribas Silva, 2003). But cement-based materials are also exposed to the elements (humidity, acidic rain, snow...) which leads to cement compounds leaching (Barbieri Albert, 2002). In our case, carbonation is followed by leaching operation. This allows us to obtain a surface $\mathrm{pH}$ about 8.8 after 30 days, and also to have two ways of weathering involved in natural weathering of materials (Wiktor, 2008).

Staining with periodic acid Schiff's reagent provides interesting results. All the controls (with and without the addition of medium, non-weathered, carbonated, carbonated then leached) appeared, after PAS staining, pale purple coloured which points out the absence of microbial growth. For carbonated specimens, a deep purple coloration is observed only for sample exposed to A. alternata. For carbonated then leached specimens, all samples are coloured in deep purple in homogeneous way and all over the exposed surface. This confirms previous observations, that leached specimens exhibited a higher microbial colonisation. PAS staining allows a better visualization of microbial development extent: in fact, PAS staining reveals that microbial activity is spread not only all over the surface but also, as demonstrated by observations of cross section (Fig. 4) that fungi penetrate within the matrix.
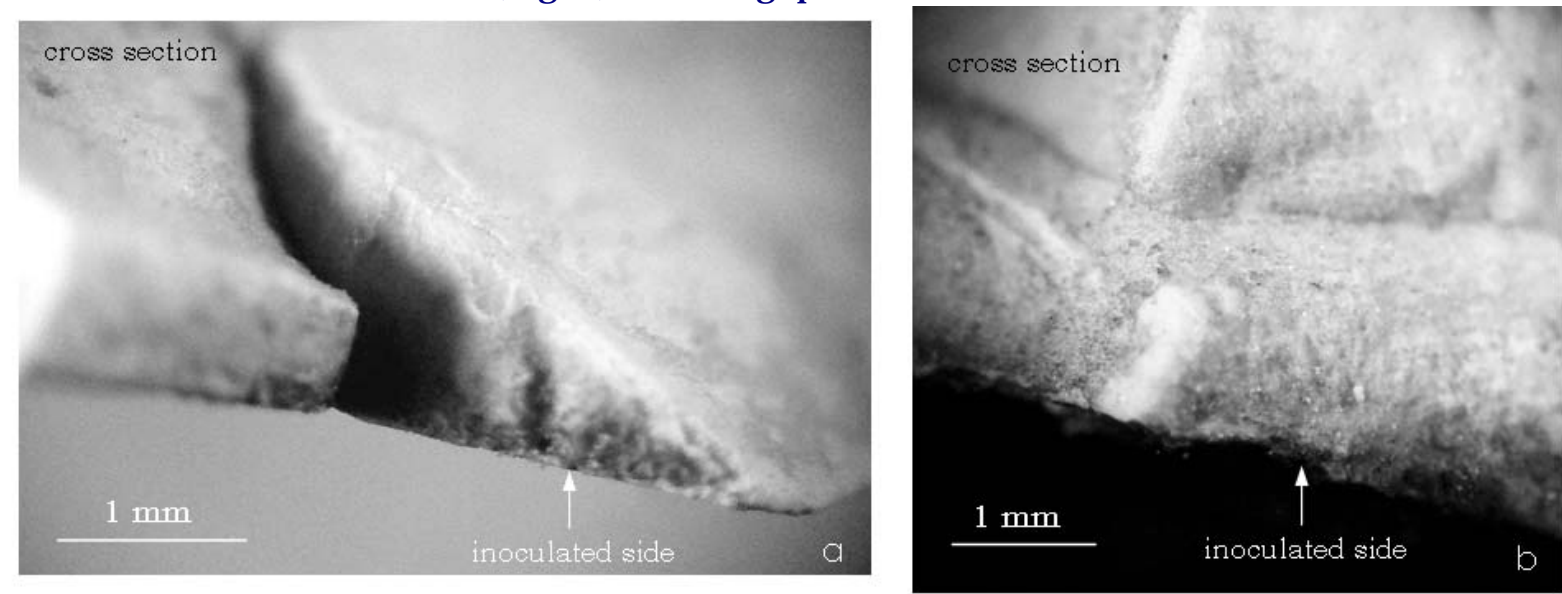

Figure 4 : Observations with stereomicroscope of samples after PAS staining, a) leached control, b) leached sample inoculated with Coniosporium uncinatum

SEM observations of the surface and the cross section were performed. The most interesting observations were noticed for carbonated then leached samples. In particularly, for samples inoculated with A. alternata and with C. uncinatum, hyphae were observed within the matrix, they penetrated through the cracks generated with accelerated weathering of the matrix (Fig. 5). From these observations depth of microbial colonisation can be estimated about $130 \mu \mathrm{m}$.

All the reference strains used where strains isolated from rocks and stone and thus already well adapted to survive on decayed stones. The strains presented different patterns of growth: Exophiala sp. develops from spots whereas A. alternata produces spores and also develops mycelium; the use of $\mathrm{C}$. uncinatum was particularly encouraging as it presented a good growth all over the incubation time. 

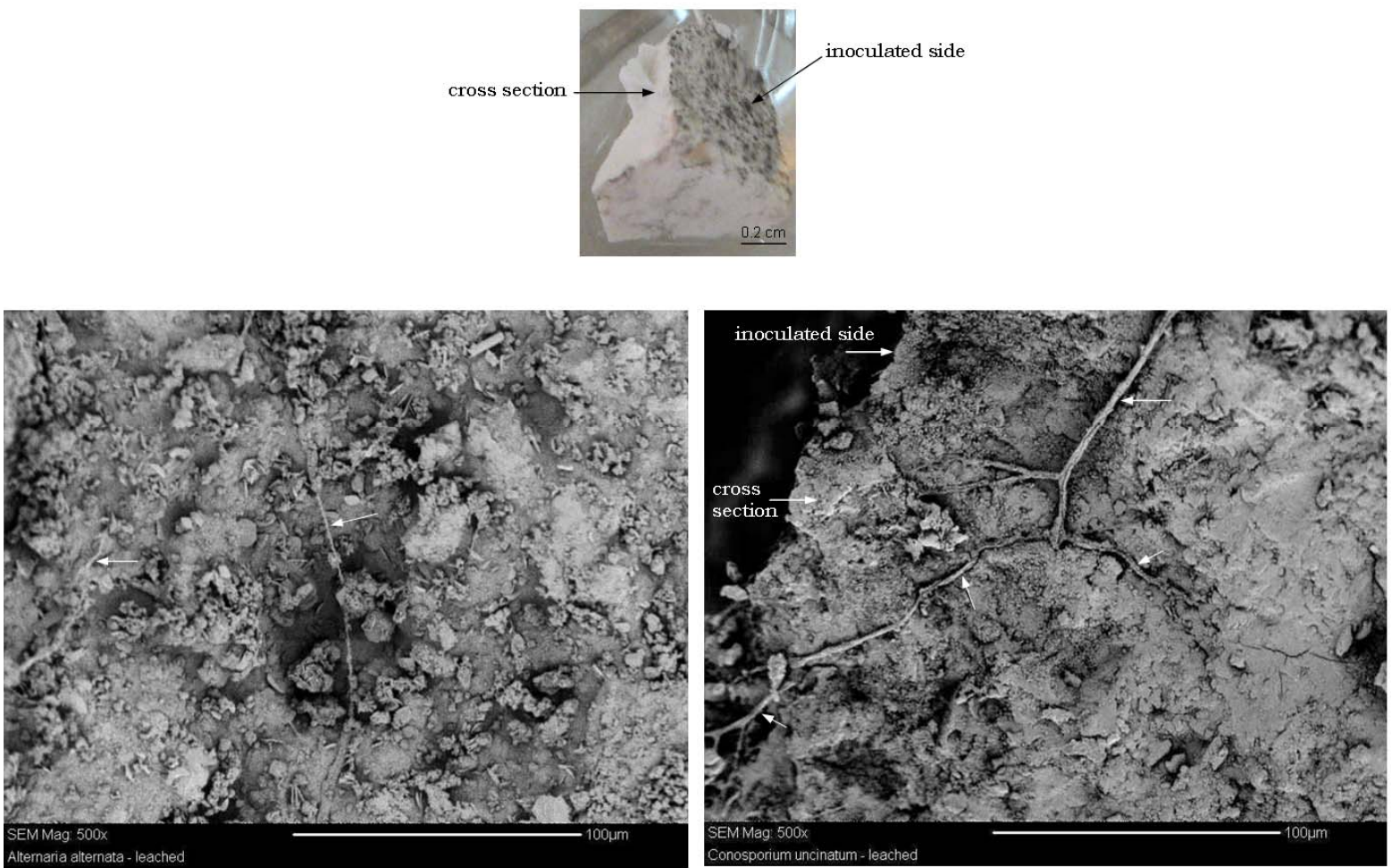

Figure 5 : SEM observations of cross sections of leached samples, arrows indicate hyphae localisation.

The accelerated laboratory test developed in this study permits to obtain a rapid fungal development on cement specimens. Three months of experiments only are needed to obtain first results, which is rather shorter than other test developed to date to study fungal biodeterioration. Results are mainly related to aesthetical biodeterioration.

This accelerated laboratory test may be used in different applications. Nowadays cement based materials contain more and more organic species used as adjuvant in order to enhance materials properties, but it brings organic matter to the matrix, and thus could enhance its primary bioreceptivity. Test can be used with short time of incubation, 4 weeks as described in this paper, to test and to compare bioreceptivity of cement based materials. On the other hand, accelerated test used with several months of incubation should allow to study mechanisms involved in biodeterioration, and also the impact of microbial growth on matrix properties, using microindentation for example.

\section{Acknowledgements}

This work was supported by the "GEM materiaux de constructions" within the project "Biodeterioration of cementitious matrix by fungi".

The Authors would like to thank Paul J ouffrey for his help in SEM analysis and Christine Lors for their advices. 
International Biodeterioration \& Biodegradation, 2009, 63(8), 1061-1065

doi: 10.1016/j.ibiod.2009.09.004

\section{References}

Barbieri Albert, B., 2002. Altération de matrices cimentaires par des eaux de pluie et des eaux sulfatées : approche expérimentale et thermodynamique, $\mathrm{PhD}$ thesis, Ecole Nationale Supérieure des Mines de Saint-Etienne et Institut National Polytechnique de Grenoble, Saint-Etienne, France.

De Hoog, G.S., 1993. Evolution of black yeasts: possible adaptation to human host, Anton van Leeuw 63, 105-109.

De la Torre, M.A., Gomez-Alarcon, G., Melgarejo, P., Saiz-Jimenez, C., 1991. Fungi in weathered sandstone from Salamanca cathedral (Spain), The Science of The Total Environment 107, 159-168.

De Leo, F., Urzì, C., de Hoog, G. S., 1999. Two Coniosporium species from rock surfaces, Studies in Mycology 43, 70-79.

De Leo, F., Urzì,, C., 2003. Fungal colonization on treated and untreated stone surfaces. In: Saiz-Jimenez (Eds.), Molecular Biology and Cultural Heritage. Swets \& Zeitlinger BV, Lisse, The Netherlands, pp. 213- 218.

de Moraes Pinheiro, S. M., Ribas Silva, M., 2003. Alteration of concrete microstructure by biodeterioration mechanisms, Proceeding of conference on Microbial Impact on Building Materials, 48-57.

Diakumaku, E., Gorbushina, A.A., Krumbein, W.E., Panina, L., Soukharjevski, S., 1995. Black fungi on marble and limestone: an aestethical, chemical and physical problem for conservation fo monuments, The Science of The Total Environment 1676, 295-304.

Dubosc, A., 2000. Etude du developpement de salissures biologiques sur les parements en béton : mise au point d'essais accélérés de vieillissement, $\mathrm{PhD}$ thesis, Institut National de Sciences Appliquées de Toulouse, Toulouse, France.

Escadeillas, G., Bertron, P., Blanc, P., Dubosc, A., 2007. Accelerated testing of biological stain growth on external concrete walls. Part I: Development of the growth tests, Materials and Structures 40, 1061-1071.

Garcia Vallès, M., Vendrell-Saiz, M., Krumbein, W.E., Urz̀, C., 1997. Coloured mineral coatings on monument surfaces as a result of biomineralization: the case of Tarragona cathedral (Catalonia), Applied Geochemistry 12, 255-266.

Gervais, C., Garrabrants, A.C., Sanchez, F., Barna, R., Moszkowicz, P., Kosson D.S., 2004. The effects of carbonation and drying during intermittent leaching on the release of inorganic constituents of cement-based matrix, Cement and Concrete Research 34, 119131.

Gorbushina, A.A., 2007. Life on rocks, Environmental microbiology 9, 1613-1631.

Guillitte, O., 1995. Bioreceptivity: a new concept for building ecology studies. Science of the Total Environment 167, 215- 220.

Guillon, E., 2004. Durabilité des matériaux cimentaires: modelisation de l'influence des équilibres physico-chimiques sur la microstructure et les propriétés mécaniques résiduelles, PhD thesis, Ecole Normale Supérieure de Cachan, Cachan, France.

Macias, A., Kindness, A., Glasser, F.P., 1997. Impact of carbon dioxide on the immobilization potential of cemented wastes: chromium, Cement and Concrete Research 27, 215-225.

May, E., Lewis, F.J., Pereira, S., Tayler, S., Seaward, M.R.D., Allsopp, D., 1993. Microbial deterioration of building stone: a review. Biodeterioration abstracts 7, 109-123.

Nielsen, K.F., Holm, G., Uttrup, L.P., Nielsen, P.A., 2004. Mould grouth on building materials under low water activity. Influence of humidity and temperature on fungal 
growth and secondary metabolism, International Biodeterioration \& Biodegradation 54, 325-336.

Ohsima, A., Matsui, I., Yuasa, N., Henmi, Y., 1999. A study on growth of fungus and algae on mortar, Transactions of the J apan Concrete Institute 21, 173-178.

Saiz-Jimenez, C., 1997. Biodeterioration vs Biodegradation the role of microorganisms in the removal pollutants deposited on historic building, International Biodeterioration \& Biodegradation 40, 225-232.

Shirakawa, M.A., Beech, I.B., Tapper, R., Cincotto, M.A., Gambale, W., 2003. The development of a method to evaluate bioreceptivity on indoor mortar plastering to fungal growth, International Biodeterioration \& Biodegradation 51, 83-92.

Sterflinger, K., 1995. Geomicrobiological investigations on the alteration of marble monuments by dematiaceous fungi (Sanctuary of Delos, Cyclades, Greece), $\mathrm{PhD}$ Thesis, University of Oldenburg, Oldenburg, Germany.

Urzì, C., Albertano, P., 2001. Studying phototrophic and heterotrophic microbial communities on stone monuments, Methods in Enzymology 336, 340-355.

Urzi, C., De Leo, F., 2007. Evaluation of the efficiency of a water repellent and biocide compounds against microbial colonization of mortars, International Biodeterioration \& Biodegradation 60, 25-34.

Urzì, C., De Leo, F., 2001. Sampling with adhesive tape strips: an easy and rapid method to monitor microbial colonization on monument surfaces. Journal of Microbiological Methods 44, 1- 11.

Urzì, C., De Leo, F., de Hoog, G.S., Sterflinger,k K. 2000. Recent advances in the molecular biology and ecophysiology of meristematic stone-inhabiting fungi. In: Ciferri, O., Tiano P., Mastromei, G. eds. Proccedings of the International Congress on Microbes and Art, Plenum Publishing Co. Ltd., New York, pp. 3-19.

Urzì, C., Realini, M., 1998. Colour changes of Noto's calcareous sandstone as related with its colonization by microorganisms. International Biodeterioration \& Biodegradation 42, 45- 54.

Urzi, C., Salamone, P., Schumann, P., Stackebrandt, E., 2000b. Marmoricola aurantiacus gen. nov., sp. nov., a coccoid member of the family Nocardioidaceae isolated from a marble statue. International J ournal of Systematic and Evolutionary Microbiology 50, 529- 536.

Warscheid, Th., Braams, J., 2000. Biodeterioration of stone: a review. International Biodeterioration \& Biodegradation 46, 343-368.

Wiktor, V., 2008. Biodeterioration d'une matrice cimentaire par des champignons: mise au point d'un test accelere de laboratoire, PhD thesis, Ecole Nationale Superieure des Mines de Saint-Etienne, Saint-Etienne, France.

Wiktor, V., Grosseau, P., Guyonnet, R., Garcia-Diaz, E., 2006. Biodétérioration d'une matrice cimentaire par les champignons: influence du vieillissement accéléré sur le développement fongique, Matériaux et Techniques 94, 1-9.

Wollenzien, U., de Hoog, G.S., Krumbein, W.E., .Urzi, C., 1995. On the isolation of microcolonial fungi occurring on and in marble and other calcareous rocks. The Science of the Total Environment 167, 287- 294. 